\title{
Assistant Physicians Knowledge and Attitudes about Defensive Medical Practices, Work-Related Stress and Burnout Levels
}

\author{
Hekimlerin, Defansif Tıp Uygulamaları Hakkındaki Bilgi ve Tutumları, İşe \\ Bağlı Gerginlik ve Tükenmişlik Düzeyleri
}

\author{
Ömer Göcen ${ }^{I}$, Ahmet Yllmaz ${ }^{1}$, Hamza Aslanhan ${ }^{1}$, Tahsin Çelepkolu ${ }^{1}$, Suheyp Tuncay ${ }^{1}$, Emre Dirican ${ }^{2}$
}

\begin{abstract}
Introduction: Defensive medicine is the practice of physicians to use the unnecessary procedures for diagnosis and treatment in order to protect themselves against medical malpractice cases, or to avoid taking the responsibility of high-risk medical practices which are likely to result in a malpractice case. The present study was carried out to reveal the knowledge and attitudes of research assistants working in internal and surgical medical sciences at Dicle University Medical Faculty Hospital about the defensive medicine applications and the factors affecting work-related stress and burnout levels. Method: The sample of this descriptive-cross-sectional type of study was designed by proportional layer method. The questionnaire, which included the sociodemographic data form, the defensive medicine applications attitude scale and the maslach burnout inventory, was applied to 200 physicians. Results: Of all the participants whose mean age was $29.4 \pm 3.0,70.5 \%(\mathrm{n}=141)$ were male, $56 \%(\mathrm{n}=112)$ were married. The frequency of positive and negative defensive medicine was found as $98 \%(\mathrm{n}=196)$ and $92 \%(\mathrm{n}=184)$ respectively. The points of defensive medicine were significantly high in the males, those working at surgical departments, those in the first two years of the specialist training in medicine, those the malpractice case opened about and smokers. The level of work-related tension was significantly high in the ones working at surgical departments, ones who keep watch for eight times or more per month, those the malpractice case opened about, smokers and alcohol users. The average points which the physicians took from Maslach Burnout Inventory were determined as $31.57 \pm 11.67$ for emotional exhaustion, $11.75 \pm 6.49$ for desensitization and $29.46 \pm 7.72$ for personal accomplishment. Conclusion: In our study, it was concluded that most of the research assistants were not satisfied with the choice of profession and specialty, their knowledge of defensive medicine concept was inadequate and their high burnout rates were found in all burnout dimensions. It was seen that the burnout levels of those who applied more to defensive medicine were higher.
\end{abstract}

Key words: Defensive medicine, malpractice, burnout

\section{ÖZET}

Giriş: Defansif tıp, hekimlerin kendilerini tıbbi malpraktis davalarına karşı korumak amacı ile tanı ve tedaviye yönelik gereksiz işlemler kullanmaları veya malpraktis davası ile sonuçlanma riski yüksek tıbbi uygulamaların sorumluluğunu almamak için, bu tür uygulamalardan kaçınmalarıdır. Bu çalışma, Dicle Üniversitesi Tıp Fakültesi Hastanesinde, dahili ve cerrahi tıp bilimlerinde çalışan araştırma görevlisi hekimlerin, defansif tıp uygulamaları hakkındaki bilgi ve tutumları, ișe bağlı gerginlik ve tükenmișlik düzeylerini etkileyen faktörleri ortaya koymak amacıyla yapılmıștır. Yöntem: Tanımlayıcı-kesitsel tipteki bu çalışmanın örneklemi, orantılı tabakalı yöntemle oluşturulmuştur. Sosyodemografik veri formu, defansif tıp uygulamaları tutum ölçeği ve Maslach tükenmişlik ölçeğini içeren anket, 200 hekime uygulanmıştır. Bulgular: Yaş ortalaması 29,4 3,0 olan katılımcıların, \% 70,5'i (n=141) erkek, \%56'sı $(\mathrm{n}=112)$ evliydi. Pozitif ve negatif defansif tıp sıklığı, sırasıyla \%98 $(\mathrm{n}=196), \% 92(\mathrm{n}=184)$ olarak bulunmuştur. Defansif tıp puanları, erkeklerde, cerrahi bilimlerde çalışanlarda, uzmanlık eğitiminin ilk 2 yılındakilerde, hakkında malpraktis davası açılanlarda ve sigara kullananlarda anlamlı derecede yüksek bulunmuştur. İşe bağlı gerginlik düzeyi, cerrahi bilimlerde çalışanlarda, ayda 8 ve üzeri sayıda nöbet tutanlarda, hakkında malpraktis davası açılanlarda, sigara kullananlarda, alkol kullananlarda anlamlı derecede yüksek bulunmuştur. Hekimlerin, Maslach tükenmişlik ölçeğinden aldıkları puan ortalamaları,

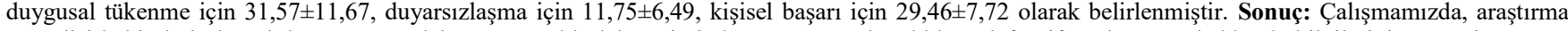
görevlisi hekimlerin büyük kısmının meslek ve uzmanlık dalı seçiminden memnun olmadıkları, defansif tıp kavramı hakkında bilgilerinin yetersiz ve tüm tükenmişlik boyutlarında, yüksek tükenmişlik oranlarının olduğu sonucuna varılmıştır. Defansif tıbbı daha fazla uygulayanların tükenmişlik düzeylerinin daha yüksek olduğu görülmüştür.

Anahtar kelimeler: Defansif tıp, malpraktis, tükenmişlik

Received / Geliş tarihi:05.12.2017, Accepted / Kabul tarihi: 22.02 .2018

${ }^{1}$ Dicle Üniversitesi Tıp Fakültesi Aile Hekimliği AD. Diyarbakır

${ }^{2}$ Dicle Üniversitesi Tıp Fakültesi Biyoistatistik AD. Diyarbakır

*Address for Correspondence / Yazışma Adresi: Ahmet Yılmaz, Dicle Üniversitesi Tıp Fakültesi Aile Hekimliği A.D. Diyarbakır-TÜRKIYE, E-mail: dearahmetyilmaz@hotmail.com

Göcen Ö, Yılmaz A, Aslanhan H, TÇelepkolu T, Tuncay S, Dirican E. Hekimlerin, Defansif Tıp Uygulamaları Hakkındaki Bilgi ve Tutumları, İșe Bağlı Gerginlik ve Tükenmişlik Düzeyleri. TJFMPC, 2018; 12 (2): 77-87. DOI: 10.21763/tjfmpc.432454 


\section{GíRIŞ}

Defansif tıp uygulamaları (DTU), hekimlerin, malpraktis davalarından korunmayı amaçladıkları tıbbi uygulamalardır. DTU yaygin olarak, "hekimin, hastanın tanı ve tedavisinden ziyade, öncelikle hasta tarafindan dava edilmekten korunmak için, istediği tanısal tetkikler, tedaviler ve prosedürlerdir" şseklinde de ifade edilebilir. ${ }^{1}$ Defansif tıp, pozitif ve negatif defansif uygulamalar olmak üzere iki şekilde yapılmaktadır. Pozitif defansif tıp (PDT), hastaları malpraktis şikâyetinde bulunmaktan vazgeçirmek veya yasal süreci, yapılması gerekenin yapıldığı konusunda ikna etmek ve hoşnutsuzluktan kaynaklanabilecek olumsuz sonuçları azaltmak amacıyla, marjinal ya da tıbbi değeri olmayan ilave tanı ve tedavi yöntemlerinin uygulanmasıdır. ${ }^{2}$ Negatif defansif tıp (NDT), hasta için yapılması gerekli olduğu halde bazı uygulamaları yerine getirmeme durumudur. DTU, sağlık hizmetinin, koruyucu hizmetler, tanı koyma, tedavi etme, bilgilendirme, kayit ve belgelendirme gibi her aşamasında görülebilir.

Günümüzde teknoloji, tıp alanında yoğun bir şekilde kullanılmaktadır. Özellikle görüntüleme yöntemlerinin tanı ve tedavideki yeri oldukça önemlidir. Ancak, lüzumsuz yere uygulanan görüntüleme tetkikleri, biyopsi gibi girişimsel ve sezaryen gibi cerrahi müdahaleler, hastaya fiziksel ve manevi açıdan zarar verebilir. Aynı zamanda, DTU sağlık harcamalarında maliyeti arttırabilmektedir. ${ }^{3}$

İşe bağlı gerginlik (İBG), kişinin çevredeki stresörlere karşı verdiği psikolojik tepkiler olarak tanımlanmaktadır. İBG ve iş stresi, birbirinin yerine kullanılan kavramlar olarak karşımıza çıkmaktadır. İBG ve tükenmişlik daha çok hekimlik, hemşirelik, fizyoterapistlik gibi insanlarla yoğun ve süreğen ilişkide olan mesleklerde görülmektedir. Sağlık alanında çalışanlarda, yoğun iş yükü, ağır ve ölümcül hastalara bakım verme, gerektiğinde hasta ve yakınlarına duygusal destek vermek zorunda kalma gibi nedenler işle ilgili gerginliğe yol açabilmektedir. ${ }^{4}$

Maslach ve Jackson, tükenmişliği, duygusal tükenme (DT), duyarsızlaşma (D) ve kişisel başarıda $(\mathrm{KB})$ düşme ile ifade edilen "üç boyutlu bir psikolojik sendrom" olarak tanımlamışlardır. DT, kişinin mesleği tarafından tüketilmiş ya da aşırı yüklenilmiş olma duygularını, D, çalışanların, hizmet verdikleri kişilere karşı duygudan yoksun ve umursamaz bir şekilde davranmalarını, KB noksanlığı ise bireylerin sorunların üstesinden gelememe, bireysel beceri ve başarıda düşme durumlarını ifade etmektedir. Hem İBG'nin, hem de tükenmişliğin yorgunluk, depresyon, düşük iş memnuniyeti ve kardiyovasküler hastalıkların da içinde olduğu, stres bağlantılı hastalıklara yol açtığı bilinmektedir. ${ }^{5}$

Literatürde, Türkiye'de ve Dünya'da defansif tıp, IBG ve tükenmişlik hakkında, her biri için ayrı çeşitli yayınlar mevcut olup, bu üç konunun bir arada işlendiği bir çalışma örneğine rastlanmamıştır. Bazı çalışmalarda, İBG ve tükenmişlik konularının bir arada işlendiği görülmüştür.

$\mathrm{Bu}$ çalışma, Dicle Üniversitesi Tıp Fakültesinde (DÜTF) çalışan araştırma görevlisi hekimlerin, tıbbi malpraktis davalarına ne sıklıkta maruz kaldığı, DTU'nun, İBG ve tükenmişlik düzeylerinin ne durumda olduğunu tespit etmek, ortaya çıkabilecek kötü sonuçların engellenmesi adına neler yapılabileceğini değerlendirmek amacıyla yapılmıştır.

\section{MATERYAL METOD}

Tanımlayıcı kesitsel tipteki bu çalışmanın evrenini, DÜTF'de çalışan dahili ve cerrahi tıp bilim dallarındaki araştırma görevlileri oluşturmuştur. $\mathrm{Bu}$ çalışma için, Dicle Üniversitesi Tıp Fakültesi girişimsel olmayan klinik araştırmalar Etik Kurulundan 02.06.2016 tarih ve 217 sayı ile onay alınmıştır. Araştırmadaki güç (power), \%80 olacak şekilde örnek hacmi hesaplandığında, minimum 172 kişi olması gerektiği görülmüş olup, tarafımızca 200 kişiye ulaşılmıştır. Orantılı tabakalı örneklem yöntemi kullanılarak, ilgili hastanedeki 14 cerrahi branş, 12 dahili branşta çalışan araştırma görevlilerinin, hem dahili ve cerrahi bilim dallarına göre hem de bilim dallarında yer alan branşlara göre katılımcılar belirlenerek örneklem grubu oluşturulmuştur. Temel tıp bilimlerindeki araştırma görevlilerinin, bir kısmının tıp fakültesi mezunu olmaması, bir kısmının da defansif tıp uygulamaları (DTU) ölçeğinin içerisinde sorgulanan hasta muayenesi, reçete yazma, hasta yatırma gibi durumlara sıklıkla müdahil olmamasından dolayı, temel bilimlerdeki araştırma görevlileri çalışmaya dahil edilmemiştir.

Çalışmanın verileri; 01-30/11/2016 tarih aralığında, sosyodemografik veri formu, DTU ölçeği, İBG ölçeği, MTÖ ve beraberinde, hekimlik mesleği ve hekimlerin çalıştıkları branş hakkındaki düşünceleri ve defansif tıp ile ilgili bilgi ve ilgileri hakkındaki soruları içeren anketlerin uygulanması ile toplanmıştır.

Çalışmamızda veriler; \%95 güvenle, SPSS 18 (Statistical Package for the Social Sciences) paket programı kullanılarak analiz edildi. Kullanılan istatistiksel testlerin önemlilik sınırı 0,05 olarak belirlenmiştir. Normal dağılım gösteren veriler için parametrik testler, göstermeyenler için parametrik olmayan testlerle analiz yapılmıştır. 
Kategorik değiş̧kenlerin analizi için ki- kare test, demografik özellikler için tanımlayıcı istatistikler kullanıldı ve ayrica Spearman korelasyon analizi yapılmıştır.

Çalışmada kullanılan DTU Tutum Ölçeği, Başer ve arkadaşları tarafından geliştirilmiştir. Kendileri tarafindan yapılmış çalışmasının güvenilirlik analizinde, ölçeğin iç tutarlılığı yüksek bulunmuştur (Cronbach alfa $=0,853$ ). Alt ölçekler için hesaplanan Cronbach alfa değerleri de PDT için 0,685 ve NDT için 0,918 olarak bulunmuştur. ${ }^{6,7}$ Katılımcının, sorulara verdiği yanıtları daha kesin bir ifade ile belirtmek için, ölçekte yer alan "tamamen katılıyorum", “çok katılıyorum”, "orta derece katıliyorum" yanitları evet olarak, "az katılıyorum" ve "hiç katılmıyorum" yanıtları hayır olarak kategorize edilmiştir.

İşe bağlı gerginlik (İBG) Ölçeği, Revicki ve arkadaşları tarafından geliştirilmiş, 18 madde içeren 4'lü likert tipi bir özbildirim ölçeğidir. ${ }^{8}$ Aslan ve arkadaşları tarafından geçerlik ve güvenirliği yapılmış ve Türkçe'ye uyarlanmıştır. 15. Madde, güvenirlik katsayılarını belirgin biçimde düşürdüğü için çalışmalarında bu maddeyi çıkartmışlardır. Ölçekten, 15. madde çıkarıldığında Cronbach alfa katsayısı 0,78 olarak bulunmuştur. ${ }^{9}$ Bu çalışmada da, ölçeğin 17 madde içeren formu kullanılmıştır.

MTÖ’nün Türkiye için geçerlilik ve güvenirlilik çalışması Ergin ve arkadaşları tarafından yapılmıştır. Cronbach Alfa katsayıları DT için 0,83 , D için 0,71 ve $\mathrm{KB}$ için 0,72 olarak bulunmuştur. $^{10} \mathrm{Bu}$ çalışmada, 22 sorudan, 7 basamaklı cevap seçeneğinden oluşan orijinal form kullanılmıştır. Tükenmişliğin, bu üç yönü arasındaki ilişkiyle ilgili olarak, her alt ölçeğin puanı ayrı olarak değerlendirilmekte ve tek bir toplam puanla birleştirilmemektedir. Sonuç olarak, her birey için üç ayrı puan hesaplanmaktadır. Ölçekten elde edilen puanlar yorumlanırken; DT puanı için; 0-16 arası düşük, 17-26 arası orta, 27 ve üzeri yüksek, D puanı için; 0-6 arası düşük, 7-12 arası orta, 13 ve üzeri yüksek, KB puanı için; 39 ve üzeri düşük, 32-38 arası orta, 0-31 arası yüksek olarak olarak sınıflandırılmıştır. Tükenmişliği olan bireylerde DT ve D puanlarının yüksek, KB puanının düşük olması beklenmektedir. ${ }^{11}$

\section{BULGULAR}

Katılımcıların \%57,5'inin ( $\mathrm{n}=115) 29$ yaş ve altında olduğu, \%70,5'inin $(\mathrm{n}=141)$ erkek, \%56,0'ının $(n=112)$ evli, \%30,5'inin $(n=61)$ çocuk sahibi olduğu tespit edildi. Katılımcıların \%65'i $(n=130)$ dahili tıp bilimlerinde görev yapmakta, \%90'1 $(n=180)$ nöbet tutmaktadır. Katılımcıların diğer sosyodemografik özellikleri Tablo 1'de verilmiştir.
Katılımcıların, hekimlik mesleği seçimi hakkındaki soruya \%28'i $(n=56)$, uzmanlık branşı seçimi hakkındaki soruya \%48'i $(n=96)$ "doğru seçim yaptığımı düşünüyorum” şeklinde yanıt vermiştir. Verilen diğer yanıtlar Şekil 1'de görülmektedir.

Hekimlerin "Eğer bir seçim yapma şansınız olsa idi ve en başa dönebilseydiniz, yine hekimlik mesleğini seçer miydiniz?" sorusunu, $\% 40$ '1 (n=80) "evet", \%27,5'i (n=55) "hayır", $\% 32,5$ 'i $(n=65) \quad$ "kararsızım" şeklinde yanıtlamıştır.

Hekimlerin, $\% 10,5$ 'i $(n=21)$ hakkında daha önce malpraktis iddiasıyla dava açıldı ̆̆ 1 \% $\% 57,5$, inin $(n=115)$ DTU kavramını daha önce hiç duymadığı tespit edilmiştir (Şekil 2).

Hekimlerden sadece üçü, DTU sorularının tamamına hayır demiştir. Katılımcıların \%98'i $(\mathrm{n}=196)$ PDT sorularından en az birisine, \%92'si $(\mathrm{n}=184)$ NDT sorularından en az birisine evet yanıtını vermiştir ( Tablo 2).

Çalışmaya katılan hekimlerin, çalıştıkları tıp bilim dallarına göre, DTU tutumları karşılaştırıldığında, dahili ve cerrahi tıp bilimleri arasında defansif tıp tutumları açısından istatistiksel olarak anlamlı fark olmamasına karşın $(p=0,47)$, DTU puan ortalaması ile tıp bilim dalı arasında istatistiksel olarak anlaml bir fark mevcut idi $(\mathrm{p}<0,05)$. DTU puan ortalamaları, erkeklerde, kadınlara göre, cerrahi bilimlerde çalışanlarda, dahili bilimlerde çalışanlara göre, uzmanlık eğitiminin 1.-2. yılında olanlarda, 3.-5. yılında olanlara göre, ayda 8 ve üzeri sayıda nöbet tutanlarda, daha az nöbet tutanlara göre, hakkında açılmış malpraktis davası olanlarda, olmayanlara göre, sigara kullananlarda, kullanmayanlara göre istatistiksel olarak anlamlı derecede fark yüksek bulunmuştur. Medeni durum, yaş, çocuk varlığı, meslekteki çalışma süresinin DTU puanı arasında istatistiksel olarak anlamlı fark bulunamamıştır (Tablo3,4).

Çalışmada, İBG puan ortalaması $41,36 \pm 7,44$ idi. İBG puan ortalamas1, cerrahi bilimlerde çalışanlarda, dahili bilimlerde çalışanlara göre, 30 yaş üzerinde olanlarda, daha küçük yaştakilere göre, ayda 8 ve üzeri sayıda nöbet tutanlarda, daha az nöbet tutanlara göre, sigara kullananlarda, kullanmayanlara göre, alkol kullananlarda, kullanmayanlara göre istatistiksel olarak anlamlı derecede yüksekti ( $p$ değerleri sirasiyla; $p=0,009 ; \quad p=0,02 ; \quad p=0,005 ; \quad p=0,005$; $\mathrm{p}=0,047$; Tablo 3,4). Hakkında açılmış malpraktis davası olanlarda, olmayanlara göre İB puan ortalaması daha yüksek olup, bu fark kısmen istatistiksel olarak anlamlıdır ( $p=0,053$; Tablo 4). Cinsiyet, medeni durum, uzmanlık eğitimi yılı, çocuk varlığı, meslekteki çalışma süresinin İBG 
puanı ile arasında istatistiksel olarak anlamlı fark bulunamamıştır ( $\mathrm{p}>0,05$; Tablo 3,4).
Çalışmada, DT puan ortalaması $31,57 \pm 11,67$ idi. DT puan ortalaması, uzmanlık

\begin{tabular}{|c|c|c|}
\hline$\underline{\text { Sosyodemografik özellikler }(n=200)}$ & $\underline{\mathbf{n}}$ & $\underline{\%}$ \\
\hline \multicolumn{3}{|l|}{ Yaș grupları (yıl) } \\
\hline 29 ve alt1 & 115 & 57,5 \\
\hline \multicolumn{3}{|l|}{30 ve üstü } \\
\hline Kadın & 59 & 29,5 \\
\hline Medeni durum & 141 & 70,5 \\
\hline Medenı durum Evli & 112 & 56.0 \\
\hline Bekar & 84 & 42,0 \\
\hline Boşanmış & 4 & 2,0 \\
\hline \multirow{2}{*}{\multicolumn{2}{|c|}{ Çocuk varlığı }} & 0,0 \\
\hline & 61 & 30,5 \\
\hline Hayır & 139 & 69,5 \\
\hline \multicolumn{3}{|l|}{ Tıp Bilim Dalı } \\
\hline Dahili Tıp Bilimleri & 130 & 65,0 \\
\hline Cerrahi Tip Bilimleri & 70 & 35,0 \\
\hline \multicolumn{3}{|l|}{ Hekim Olarak Çalışma Süresi } \\
\hline $0-5$ y1l & 138 & 69,0 \\
\hline 6 ve üzeri yıl & 62 & 31,0 \\
\hline \multicolumn{3}{|l|}{ Uzmanlık eğitimi yılı } \\
\hline $1-2 . \mathrm{y} 1 \mathrm{l}$ & 121 & 60,5 \\
\hline 3-5. y1l & 79 & 39,5 \\
\hline \multicolumn{3}{|l|}{ Nöbet tutma durumu } \\
\hline Hayır & $\begin{array}{l}180 \\
20\end{array}$ & 90,0 \\
\hline \multicolumn{3}{|l|}{ Bir ayda tutulan ortalama nöbet sayısı } \\
\hline 0- 7 gün & 121 & 60,5 \\
\hline 8 ve üzeri gün & 79 & 39,5 \\
\hline \multicolumn{3}{|l|}{ Sigara kullanım durumu } \\
\hline Evet & 47 & 23,5 \\
\hline Hayır & 150 & 75,0 \\
\hline \multirow{2}{*}{\multicolumn{3}{|c|}{ Alkol kullanım durumu }} \\
\hline & & \\
\hline Evet & 35 & 17,5 \\
\hline Hayır & 165 & 82,5 \\
\hline Biraktım & 0 & 0,0 \\
\hline
\end{tabular}

eğitiminin 1.-2. y1lında olanlarda, 3.-5. yılında olanlara göre, ayda 8 ve üzeri sayıda nöbet tutanlarda, daha az nöbet tutanlara göre, sigara kullananlarda, kullanmayanlara göre, alkol kullananlarda, kullanmayanlara göre anlamlı derecede yüksek saptanmıştır( $p$ değerleri sırasıyla; $\mathrm{p}=0,001 ; \mathrm{p}=0,001 ; \mathrm{p}=0,001 ; \mathrm{p}=0,017$; Tablo 4). Cinsiyet, medeni durum, yaş, çocuk varlığı, meslekteki çalışma süresi, çalışılan tıp bilim dalı, hakkında açılmış malpraktis dava olmasının DT puanı ile arasında istatistiksel olarak anlamlı fark bulunamamıştır ( $\mathrm{p}>0,05$; Tablo 3,4).

Çalışmada, D puan ortalaması $11,75 \pm 6,49$ idi. D puan ortalaması, cerrahi bilimlerde çalışanlarda, dahili bilimlerde çalışanlara göre, ayda 8 ve üzeri sayıda nöbet tutanlarda, daha az nöbet tutanlara göre, hakkında açılmış malpraktis davası olanlarda, olmayanlara göre, sigara kullananlarda, kullanmayanlara göre, alkol kullananlarda, kullanmayanlara göre istatistiksel olarak anlamlı derecede yüksek bulunmuştur ( $p$ değerleri sırasıyla; $\mathrm{p}=0,003 ; \mathrm{p}=0,01 ; \mathrm{p}=0,017 ; \mathrm{p}=0,005 ; \mathrm{p}=0,003$; Tablo 3,4). Cinsiyet, medeni durum, yaş, çocuk varlığı, meslekteki çalışma süresi, uzmanlık eğitimi yılının D puanı ile arasında istatistiksel olarak anlamlı fark bulunamamıştır ( $p>0,05$; Tablo 3,4).

Çalışmada, KB puan ortalaması 29,46 $\pm 7,72$ idi. Bağımsız değişkenlerden, KB puanını istatistiksel olarak anlamlı düzeyde etkileyen bir değişken tespit edilmemiştir (Tablo $3,4)$.

Çalışmamızda PDT ile NDT arasında $(\mathrm{r}=+0,64, \quad \mathrm{p}<0,01), \quad$ PDT ile TDT arasinda $(\mathrm{r}=+0,93, \mathrm{p}<0,01)$, NDT ile TDT arasinda $(\mathrm{r}=+0,87, \mathrm{p}<0,01)$ korelasyon saptanmıştır. PDT ile İBG arasinda $(\mathrm{r}=+0,36, \mathrm{p}<0,01)$, NDT ile İBG arasinda $(\mathrm{r}=+0,46, \mathrm{p}<0,01)$, TDT ile İBG arasinda 
$(\mathrm{r}=+0,44, \mathrm{p}<0,01)$, DT ile İBG arasında $(\mathrm{r}=+0,71$, $\mathrm{p}<0,01)$, DT ile D arasinda $(\mathrm{r}=+0,64, \mathrm{p}<0,01), \mathrm{KB}$ ile DT arasinda $(\mathrm{r}=-0,18, \mathrm{p}<0,01)$ korelasyon saptanmıştır (Tablo 5).

Tablo 2. Katılımcıların, DTU ölçek sorularına verdikleri yanıtların dağılımı

\begin{tabular}{|c|c|c|c|c|c|}
\hline SORU & $\begin{array}{l}\text { Tamamen } \\
\text { katiliyorum }\end{array}$ & $\begin{array}{c}\text { Çok } \\
\text { kat1lyyorum }\end{array}$ & $\begin{array}{c}\text { Orta } \\
\text { derecede } \\
\text { kat1liyorum }\end{array}$ & $\begin{array}{c}\mathrm{Az} \\
\text { kat1lyorum }\end{array}$ & $\begin{array}{c}\text { Hiç } \\
\text { katılmıorum }\end{array}$ \\
\hline $\begin{array}{l}\text { 1. Hukuki sorunlardan korunmak amacı } \\
\text { ile hastalarımdan gerekli gördüklerimin } \\
\text { dişında tetkikler istiyorum. }\end{array}$ & $\begin{array}{c}29 \\
(\% 14,5)\end{array}$ & $\begin{array}{c}27 \\
(\% 13,5)\end{array}$ & $\begin{array}{c}80 \\
(\% 40,0)\end{array}$ & $\begin{array}{c}37 \\
(\% 18,5)\end{array}$ & $\begin{array}{c}27 \\
(\% 13,5)\end{array}$ \\
\hline $\begin{array}{l}\text { 2. Hukuki sorunlardan korunmak amacı } \\
\text { ile hastalarıma endikasyonları dahilinde } \\
\text { yazabileceğim ilaçların çoğunu } \\
\text { yazıyorum. }\end{array}$ & $\begin{array}{c}30 \\
(\% 15,0)\end{array}$ & $\begin{array}{c}64 \\
(\% 32,0)\end{array}$ & $\begin{array}{c}56 \\
(\% 28,0)\end{array}$ & $\begin{array}{c}31 \\
(\% 15,5)\end{array}$ & $\begin{array}{c}19 \\
(\% 9,5)\end{array}$ \\
\hline $\begin{array}{l}\text { 3. Hukuki sorunlardan korunmak amacı } \\
\text { ile hastalarımda gelişebilecek } \\
\text { komplikasyonlar ile ilgili daha fazla } \\
\text { konsültasyon istiyorum. }\end{array}$ & $\begin{array}{c}50 \\
(\% 25,0)\end{array}$ & $\begin{array}{c}72 \\
(\% 36,0)\end{array}$ & $\begin{array}{c}47 \\
(\% 23,5)\end{array}$ & $\begin{array}{c}20 \\
(\% 10,0)\end{array}$ & $\begin{array}{c}11 \\
(\% 5,5)\end{array}$ \\
\hline $\begin{array}{l}\text { 4. Hukuki sorunlardan korunmak amacı } \\
\text { ile endikasyonları dişı nedenler ile (örn: } \\
\text { sosyal endikasyon) hastayatırıyorum. }\end{array}$ & $\begin{array}{c}18 \\
(\% 9,0)\end{array}$ & $\begin{array}{c}32 \\
(\% 16,0)\end{array}$ & $\begin{array}{c}44 \\
(\% 22,0)\end{array}$ & $\begin{array}{c}57 \\
(\% 28,5)\end{array}$ & $\begin{array}{c}49 \\
(\% 24,5)\end{array}$ \\
\hline $\begin{array}{l}\text { 5. Hukuki sorunlardan korunmak amacı } \\
\text { ile görüntüleme tekniklerini daha sık } \\
\text { kullanıyorum. }\end{array}$ & $\begin{array}{c}37 \\
(\% 18,5)\end{array}$ & $\begin{array}{c}52 \\
(\% 26,0)\end{array}$ & $\begin{array}{c}58 \\
(\% 29,0)\end{array}$ & $\begin{array}{c}30 \\
(\% 15,0)\end{array}$ & $\begin{array}{c}23 \\
(\% 11,5)\end{array}$ \\
\hline $\begin{array}{l}\text { 6. Hukuki sorunlardan korunmak amacı } \\
\text { ile tıbbi uygulamaları hastalarıma daha } \\
\text { detaylıaçıklıyorum. }\end{array}$ & $\begin{array}{c}55 \\
(\% 27,5)\end{array}$ & $\begin{array}{c}69 \\
(\% 34,5)\end{array}$ & $\begin{array}{c}46 \\
(\% 23,0)\end{array}$ & $\begin{array}{c}21 \\
(\% 10,5)\end{array}$ & $\begin{array}{c}9 \\
(\% 4,5)\end{array}$ \\
\hline $\begin{array}{l}\text { 7. Hukuki sorunlardan korunmak amacı } \\
\text { ile hastalarıma daha fazla zaman } \\
\text { ayırıyorum. }\end{array}$ & $\begin{array}{c}24 \\
(\% 12,0)\end{array}$ & $\begin{array}{c}31 \\
(\% 15,5)\end{array}$ & $\begin{array}{c}63 \\
(\% 31,5)\end{array}$ & $\begin{array}{c}51 \\
(\% 25,5)\end{array}$ & $\begin{array}{c}31 \\
(\% 15,5)\end{array}$ \\
\hline $\begin{array}{l}\text { 8. Hukuki sorunlardan korunmak amacı } \\
\text { ile kayıtları daha detaylı tutuyorum. }\end{array}$ & $\begin{array}{c}56 \\
(\% 28,0)\end{array}$ & $\begin{array}{c}68 \\
(\% 34,0)\end{array}$ & $\begin{array}{c}58 \\
(\% 29,0)\end{array}$ & $\begin{array}{c}14 \\
(\% 7,0)\end{array}$ & $\begin{array}{c}4 \\
(\% 2,0)\end{array}$ \\
\hline $\begin{array}{l}\text { 9. Hukuki sorunlardan korunmak amacı } \\
\text { ile aydınlatılmıs onam formlarına daha } \\
\text { fazla önemveriyorum. }\end{array}$ & $\begin{array}{c}74 \\
(\% 37,0)\end{array}$ & $\begin{array}{c}82 \\
(\% 41,0)\end{array}$ & $\begin{array}{c}29 \\
(\% 14,5)\end{array}$ & $\begin{array}{c}10 \\
(\% 5,0)\end{array}$ & $\begin{array}{c}5 \\
(\% 2,5)\end{array}$ \\
\hline $\begin{array}{l}\text { 10. Hukuki sorunlardan korunmak } \\
\text { amacı ile dava etme olasılığı yüksek } \\
\text { hastalardan kaçınıyorum. }\end{array}$ & $\begin{array}{c}47 \\
(\% 23,5)\end{array}$ & $\begin{array}{c}43 \\
(\% 21,5)\end{array}$ & $\begin{array}{c}45 \\
(\% 22,5)\end{array}$ & $\begin{array}{c}44 \\
(\% 22,0)\end{array}$ & $\begin{array}{c}21 \\
(\% 10,5)\end{array}$ \\
\hline $\begin{array}{l}\text { 11. Hukuki sorunlardan korunmak } \\
\text { amacı ile karmaşı problemleri olan } \\
\text { hastalardan kaçınıyorum. }\end{array}$ & $\begin{array}{c}35 \\
(\% 17,5)\end{array}$ & $\begin{array}{c}36 \\
(\% 18,0)\end{array}$ & $\begin{array}{c}53 \\
(\% 26,5)\end{array}$ & $\begin{array}{c}48 \\
(\% 24,0)\end{array}$ & $\begin{array}{c}28 \\
(\% 14,0)\end{array}$ \\
\hline $\begin{array}{l}\text { 12. Hukuki sorunlardan korunmak } \\
\text { amacı ile komplikasyon oranları yüksek } \\
\text { tedavi protokollerinden kaçınıorum. }\end{array}$ & $\begin{array}{c}33 \\
(\% 16,5)\end{array}$ & $\begin{array}{c}43 \\
(\% 21,5)\end{array}$ & $\begin{array}{c}60 \\
(\% 30,0)\end{array}$ & $\begin{array}{c}44 \\
(\% 22,0)\end{array}$ & $\begin{array}{c}20 \\
(\% 10,0)\end{array}$ \\
\hline $\begin{array}{l}\text { 13. Hukuki sorunlardan korunmak } \\
\text { amacı ile girişimsel tedavi protokolleri } \\
\text { yerine girişimsel olmayan protokolleri } \\
\text { tercih etmeye yöneliyorum. }\end{array}$ & $\begin{array}{c}32 \\
(\% 16,0)\end{array}$ & $\begin{array}{c}36 \\
(\% 18,0)\end{array}$ & $\begin{array}{c}57 \\
(\% 28,5)\end{array}$ & $\begin{array}{c}50 \\
(\% 25,0)\end{array}$ & $\begin{array}{c}25 \\
(\% 12,5)\end{array}$ \\
\hline
\end{tabular}


14. Malpraktis ile ilgili konular

medyada fazlaca yer buldukça hekimlik

uygulamalarımda tedirginlik

hissediyorum.

$\begin{array}{ccccc}69 & 62 & 43 & 19 & 7 \\ (\% 34,5) & (\% 31,0) & (\% 21,5) & (\% 9,5) & (\% 3,5)\end{array}$

\%3,5)

Tablo 3. Katılımcıların, bazı demografik değişkenlere göre ölçeklerden aldıkları puanlar

\begin{tabular}{|c|c|c|c|c|c|}
\hline & $\begin{array}{c}\text { Uzmanlık eğitimi } \\
\text { Yılı }\end{array}$ & $\begin{array}{c}\text { Bir Ayda Tutulan } \\
\text { Nöbet Sayısı } \\
\text { (gün/ay) }\end{array}$ & $\begin{array}{c}\text { Hakkında } \\
\text { Malpraktis Davası } \\
\text { Açılma Durumu }\end{array}$ & $\begin{array}{c}\text { Sigara Kullanım } \\
\text { Durumu }\end{array}$ & $\begin{array}{c}\text { Alkol } \\
\text { Kullanım } \\
\text { Durumu }\end{array}$ \\
\hline \multirow{3}{*}{ PDT } & 1-2 vil $3-5$ vil & $0-7>8$ & Evet Havir & Evet Havır & Evet Havir \\
\hline & $\begin{array}{l}30,8 \pm 6,6 \\
28,8 \pm 7,1\end{array}$ & $\begin{array}{l}29,0 \pm 6,9 \\
31,7 \pm 6,4\end{array}$ & $\begin{array}{l}34,3 \pm 8,0 \\
29,5 \pm 6,5\end{array}$ & $\begin{array}{l}32,8 \pm 5,9 \\
29,2 \pm 6,9\end{array}$ & $\begin{array}{l}30,8 \pm 7,4 \\
29,9 \pm 6,7\end{array}$ \\
\hline & $p=0,045$ & $p=0,006$ & $p=0,003$ & $p=0,002$ & $p=0,481$ \\
\hline \multirow[t]{2}{*}{ NDT } & $\begin{array}{l}16,8 \pm 4,8 \\
15,2 \pm 5,3\end{array}$ & $\begin{array}{l}15,6 \pm 5,0 \\
17,1 \pm 5,1\end{array}$ & $\begin{array}{l}19,5 \pm 4,9 \\
15,8 \pm 5,0\end{array}$ & $\begin{array}{l}17,9 \pm 5,2 \\
15,7 \pm 4,9\end{array}$ & $\begin{array}{l}17,3 \pm 5,4 \\
15,9 \pm 5,0\end{array}$ \\
\hline & $p=0,022$ & $p=0,05$ & $p=0,002$ & $p=0,009$ & $p=0,156$ \\
\hline \multirow[t]{2}{*}{ TDT } & $\begin{array}{l}47,7 \pm 10,3 \\
44,0 \pm 11,5\end{array}$ & $\begin{array}{l}44,6 \pm 11,1 \\
48,8 \pm 10,2\end{array}$ & $\begin{array}{l}53,8 \pm 12,2 \\
45,4 \pm 10,4\end{array}$ & $\begin{array}{c}50,7 \pm 9,3 \\
44,9 \pm 11,0\end{array}$ & $\begin{array}{l}48,1 \pm 10,9 \\
45,9 \pm 10,9\end{array}$ \\
\hline & $p=0,019$ & $p=0,008$ & $p=0,001$ & $p=0,001$ & $p=0,267$ \\
\hline \multirow[t]{2}{*}{ İBG } & $\begin{array}{l}41,6 \pm 7,1 \\
40,8 \pm 7,8\end{array}$ & $\begin{array}{l}40,1 \pm 7,5 \\
43,1 \pm 6,8\end{array}$ & $\begin{array}{l}44,3 \pm 9,5 \\
41,0 \pm 7,1\end{array}$ & $\begin{array}{l}44,0 \pm 6,9 \\
40,5 \pm 7,4\end{array}$ & $\begin{array}{l}43,6 \pm 6,7 \\
40,8 \pm 7,5\end{array}$ \\
\hline & $p=0,440$ & $p=0,005$ & $p=0,053$ & $p=0,005$ & $p=0,047$ \\
\hline \multirow[t]{2}{*}{ DT } & $\begin{array}{l}33,7 \pm 11,1 \\
28,2 \pm 11,7\end{array}$ & $\begin{array}{l}28,8 \pm 11,0 \\
35,6 \pm 11,5\end{array}$ & $\begin{array}{l}34,1 \pm 12,7 \\
31,2 \pm 11,5\end{array}$ & $\begin{array}{c}37,7 \pm 9,3 \\
29,6 \pm 11,6\end{array}$ & $\begin{array}{c}35,0 \pm 8,5 \\
30,8 \pm 12,1\end{array}$ \\
\hline & $p=0,001$ & $p=0,001$ & $p=0,288$ & $p=0,001$ & $p=0,017$ \\
\hline \multirow[t]{2}{*}{ D } & $\begin{array}{l}12,3 \pm 6,2 \\
10,8 \pm 6,7\end{array}$ & $\begin{array}{l}10,8 \pm 6,1 \\
13,2 \pm 6,7\end{array}$ & $\begin{array}{l}14,9 \pm 7,6 \\
11,3 \pm 6,2\end{array}$ & $\begin{array}{l}14,0 \pm 6,3 \\
11,0 \pm 6,3\end{array}$ & $\begin{array}{l}14,7 \pm 5,9 \\
11,1 \pm 6,4\end{array}$ \\
\hline & $p=0,106$ & $p=0,01$ & $p=0,017$ & $p=0,005$ & $p=0,003$ \\
\hline \multirow[t]{2}{*}{$\mathbf{K B}$} & $\begin{array}{l}28,8 \pm 7,4 \\
30,4 \pm 8,0\end{array}$ & $\begin{array}{l}29,4 \pm 7,4 \\
29,4 \pm 8,1\end{array}$ & $\begin{array}{l}31,4 \pm 7,0 \\
29,2 \pm 7,7\end{array}$ & $\begin{array}{l}27,8 \pm 7,0 \\
29,9 \pm 7,8\end{array}$ & $\begin{array}{l}28,5 \pm 6,7 \\
29,6 \pm 7,9\end{array}$ \\
\hline & $p=0,157$ & $p=0,995$ & $p=0,218$ & $p=0,107$ & $p=0,427$ \\
\hline
\end{tabular}

* Veriler ortalama \pm standart sapma olarak gösterilmiştir. PDT: Pozitif defansif tıp, NDT: Negatif defansif tıp, TDT: Toplam defansif tıp, İBG: İşe bağlı gerginlik, DT: Duygusal tükenme, D: Duyarsızlaşma, KB: Kişisel başarı

\section{TARTIŞMA}

Çalışmada, hekimlerin yarısından fazlası, hekimlik mesleği ve uzmanlık dalı seçimlerinden memnun olmadıkları yönünde yanı vermişlerdir. Hekimlerin, çalışmamızdaki tükenmişlik ve İBG düzeylerinin yanı sıra, ülkemizdeki sosyal ve yasal hakları, kamudaki saygınlığı, çalışan memnuniyet düzeyi, iş yükü ve aldıkları ücret gibi birçok önemli etkenin bu sonuçlarda etkisi olduğu düşünülebilir ${ }^{11,25}$.
Çalışmamızda, hekimlerin dava edilme oranları cerrahi branşlarda, dahili branşlara göre 4,6 kat fazla olduğu görülmüştür. Chen ve arkadaşları, Tayvan'da dahili ve cerrahi bilimlerde çalışan 457 hekime uyguladığı bir ankette, \%56,5'inin malpraktis dava deneyimi olduğu görülmüştür. ${ }^{12}$ İsrail'de, 877 hekime uygulanan bir çalışmada, hekimlerin \%25'inin kariyerinde en az bir kez malpraktis davasının olduğu bildirilmektedir. ${ }^{13}$ Aynacı tarafindan Konya'da hekimler arasinda yapılan bir anket çalışmasında, dava edilme oranı \%12,34 bulunmuştur. ${ }^{2} \mathrm{Bu}$ çalışmada, çalışmamıza 
benzer şekilde, dahili bilimlerdeki hekimlere karşı açılan davalar, cerrahi bilimlerdekilere açılanlardan çok daha azdır. Literatürde dava edilme riski en yüksek beş uzmanlık dalı; acil tıp, genel cerrahi, ortopedi, beyin cerrahisi, kadın hastalıkları ve doğum olarak belirtilmiştir. ${ }^{14}$ Ülkemizdeki malpraktis dava oranları daha düşük çıkmakla birlikte cerrahi branşların, dava oranlarının yüksek olması literatürle uyumludur. ${ }^{2,13,14}$

\begin{tabular}{|c|c|c|c|c|c|c|}
\hline & $\begin{array}{c}\text { Tip Bilim } \\
\text { Dalı }\end{array}$ & Cinsiyet & Medeni Durum & Yaş (yıl) & Çocuk Varlığı & $\begin{array}{c}\text { Hekim Olarak } \\
\text { Çalışma Süresi (yıl) }\end{array}$ \\
\hline & $\begin{array}{c}\text { Dahili } \\
\text { Cerrahi }\end{array}$ & Kadın Erkek & Evli Bekar & $\leq 29 \geq 30$ & Evet Hayır & $0-5 \geq 6$ \\
\hline PDT & $\begin{array}{l}28,8 \pm 6,6 \\
32,4 \pm 6,7 \\
p=0,001\end{array}$ & $\begin{array}{c}28,5 \pm 6,430,7 \pm 6,9 \\
p=0,039\end{array}$ & $\begin{array}{l}29,9 \pm 6,8 \\
30,4 \pm 7,0 \\
p=0,619\end{array}$ & $\begin{array}{l}30,2 \pm 6,6 \\
29,8 \pm 7,2 \\
p=0,697\end{array}$ & $\begin{array}{l}30,3 \pm 6,9 \\
29,9 \pm 6,9 \\
p=0,737\end{array}$ & $\begin{array}{l}30,1 \pm 6,6 \\
29,8 \pm 7,3 \\
p=0,741\end{array}$ \\
\hline NDT & $\begin{array}{l}15,5 \pm 4,9 \\
17,5 \pm 5,1 \\
p=0,007\end{array}$ & $\begin{array}{c}14,9 \pm 4,6 \quad 16,7 \pm 5,2 \\
p=0,021\end{array}$ & $\begin{array}{l}15,9 \pm 4,9 \\
16,5 \pm 5,3 \\
p=0,378\end{array}$ & $\begin{array}{l}16,2 \pm 5,2 \\
16,2 \pm 4,9 \\
p=0,936\end{array}$ & $\begin{array}{l}16,3 \pm 5,0 \\
16,1 \pm 5,1 \\
p=0,851\end{array}$ & $\begin{array}{l}16,1 \pm 5,2 \\
16,4 \pm 4,8 \\
p=0,676\end{array}$ \\
\hline TDT & $\begin{array}{c}44,3 \pm 10,4 \\
49,9 \pm 10,9 \\
p=0,001\end{array}$ & $\begin{array}{c}43,4 \pm 10,2 \\
47,4 \pm 11,0 \\
p=0,017\end{array}$ & $\begin{array}{l}45,8 \pm 10,8 \\
47,0 \pm 11,1 \\
p=0,468\end{array}$ & $\begin{array}{c}46,4 \pm 10,7 \\
46,1 \pm 11,2 \\
p=0,836\end{array}$ & $\begin{array}{l}46,6 \pm 11,0 \\
46,1 \pm 10,9 \\
p=0,765\end{array}$ & $\begin{array}{c}46,3 \pm 10,7 \\
46,2 \pm 11,3 \\
p=0,990\end{array}$ \\
\hline İBG & $\begin{array}{l}40,3 \pm 6,8 \\
43,2 \pm 8,0 \\
p=0,009\end{array}$ & $\begin{array}{l}40,8 \pm 7,0 \\
41,5 \pm 7,6 \\
p=0,526\end{array}$ & $\begin{array}{l}41,7 \pm 7,7 \\
40,6 \pm 7,0 \\
p=0,300\end{array}$ & $\begin{array}{l}40,3 \pm 7,0 \\
42,7 \pm 7,7 \\
p=0,020\end{array}$ & $\begin{array}{l}42,1 \pm 7,8 \\
41,0 \pm 7,2 \\
p=0,347\end{array}$ & $\begin{array}{l}40,6 \pm 7,0 \\
42,8 \pm 8,1 \\
p=0,055\end{array}$ \\
\hline DT & $\begin{array}{c}30,5 \pm 11,1 \\
33,4 \pm 12,4 \\
p=0,092\end{array}$ & $\begin{array}{l}31,7 \pm 11,4 \\
31,4 \pm 11,7 \\
p=0,873\end{array}$ & $\begin{array}{l}31,1 \pm 12,4 \\
32,0 \pm 10,6 \\
p=0,585\end{array}$ & $\begin{array}{c}31,3 \pm 10,9 \\
31,8 \pm 12,6 \\
p=0,768\end{array}$ & $\begin{array}{c}29,8 \pm 12,8 \\
32,3 \pm 11,0 \\
p=0,159\end{array}$ & $\begin{array}{l}31,2 \pm 11,4 \\
32,2 \pm 12,2 \\
p=0,580\end{array}$ \\
\hline D & $\begin{array}{l}10,7 \pm 5,7 \\
13,7 \pm 7,3 \\
p=0,003\end{array}$ & $\begin{array}{l}10,6 \pm 5,3 \\
12,2 \pm 6,8 \\
p=0,129\end{array}$ & $\begin{array}{l}11,3 \pm 6,6 \\
12,0 \pm 6,2 \\
p=0,498\end{array}$ & $\begin{array}{l}11,8 \pm 6,3 \\
11,6 \pm 6,7 \\
p=0,910\end{array}$ & $\begin{array}{l}11,4 \pm 6,9 \\
11,8 \pm 6,2 \\
p=0,653\end{array}$ & $\begin{array}{l}11,5 \pm 6,1 \\
12,1 \pm 7,2 \\
p=0,554\end{array}$ \\
\hline $\mathbf{K B}$ & $\begin{array}{l}28,9 \pm 7,7 \\
30,4 \pm 7,6\end{array}$ & $\begin{array}{l}29,4 \pm 7,6 \\
29,4 \pm 7,7\end{array}$ & $\begin{array}{l}29,0 \pm 7,9 \\
30,0 \pm 7,4\end{array}$ & $\begin{array}{l}29,2 \pm 7,8 \\
29,6 \pm 7,6\end{array}$ & $\begin{array}{l}29,4 \pm 8,0 \\
29,4 \pm 7,6\end{array}$ & $\begin{array}{l}29,2 \pm 7,8 \\
29,9 \pm 7,4\end{array}$ \\
\hline & $p=0,194$ & $p=0,970$ & $p=0,374$ & $p=0,714$ & $p=0,983$ & $p=0,574$ \\
\hline
\end{tabular}

* Veriler ortalama \pm standart sapma olarak gösterilmiştir. PDT: Pozitif defansif tıp, NDT: Negatif defansif tıp, TDT: Toplam defansif tıp, IBGG: İşe bağlı gerginlik, DT: Duygusal tükenme, D: Duyarsızlaşma, KB: Kişisel başarı

Çalışmamıza nazaran, DTU kavramı, hekimlerce, yurtdışında çok daha yüksek oranlarda bilinmektedir. ${ }^{15}$ Bulgularımıza göre, DTU kavramının ülkemizde henüz yeterince bilinmediği ve hekimlerin mesleki geleceği için, defansif tıp eğitim programları düzenlenmesinin gerektiği görülmektedir.

Hekimlerimizin, haklarında açılan malpraktis davaları, diğer ülkelere göre belirgin şekilde az olmasına rağmen, DTU düzeyleri diğer ülkelerle 
benzer şekilde yüksektir. Ülkemizde giderek artan malpraktis davaları, malpraktis iddialarının medyada fazlaca yer bulması, tıp hukuku hakkında hekimlerin yeterli düzeyde eğitimli olmaması ve buna bağlı olarak davalardan gereğinden fazla korkuyor olabilecekleri, hekimlerin, kendileri hakkında açılan davaları diğer hekimlerle de konuşması ve onları da bu konuda etkileyerek, malpraktis hakkındaki farkındalığı arttırmaları gibi etkenler DTU düzeylerindeki yüksek oranları açıklayabilir. $^{2}$

Tablo 5. Kullanılan ölçeklerin korelasyon analizi

\begin{tabular}{|c|c|c|c|c|c|c|c|c|}
\hline & & PDT & NDT & TDT & İBG & DT & D & KB \\
\hline PDT & $\mathrm{r}$ & 1 & & & & & & \\
\hline NDT & $\mathrm{r}$ & $0,648^{*}$ & 1 & & & & & \\
\hline TDT & $\mathrm{r}$ & $0,934^{*}$ & $0,877 *$ & 1 & & & & \\
\hline İBG & $\mathrm{r}$ & $0,363^{*}$ & $0,468 *$ & $0,448 *$ & 1 & & & \\
\hline DT & $\mathrm{r}$ & $0,274^{*}$ & $0,372 *$ & $0,347 *$ & $0,711^{*}$ & 1 & & \\
\hline D & $\mathrm{r}$ & $0,227^{*}$ & $0,365 *$ & $0,314^{*}$ & $0,498 *$ & $0,640 *$ & 1 & \\
\hline $\mathbf{K B}$ & $\mathrm{r}$ & $-0,080$ & $-0,184 *$ & $-0,137$ & $-0,271 *$ & $-0,189 *$ & $-0,119$ & 1 \\
\hline
\end{tabular}

*: p<0,01 PDT: Pozitif defansif tıp, NDT: Negatif defansif tıp, TDT: Toplam defansif tıp, İBG: İșe bağlı gerginlik, DT: Duygusal tükenme, D: Duyarsızlaşma, KB: Kişisel başarı

Çalışmamızda, hekimlerin, DTU içerisinde, hukuki sorunlardan korunmak amacı ile endikasyon dişı nedenler ile hasta yatırma uygulaması dışındaki diğer tüm uygulamalarda \%50'nin üzerinde defansif tıp uygulama eğiliminde olduğu tespit edilmiştir. Araştırmanın yapıldı̆̆ hastanenin üçüncü basamak bir hastane olması ve araştırma görevlilerinin kendileri adına değil de, ancak kendilerinden sorumlu olan öğretim görevlisi adına ve onun onayını alarak hasta yatırması nedenleriyle, bu oranın diğer uygulamalardaki oranlardan daha az çıktığı düşünülebilir.

Aslan ve arkadaşlarının yaptıkları çalışmada, araştırma görevlilerinin İBG puan ortalaması uzman hekimlere kiyasla fazla, pratisyen hekim ve hemşirelere oranla daha düşük çıkmıştır. ${ }^{9}$ Çalışmamızda hekimlerin İBG puan ortalaması
Aslan ve arkadaşlarının çalışmaları ile benzer bulunmuştur. Kullanılan ölçeğin kesim noktası bulunmaması ve ölçekten alınabilecek en yüksek puanın 68 olduğu düşünüldüğünde, hekimlerin çok fazla olmasa da İBG yaşadığı söylenebilir.

Literatür, hekimlerin, topluma göre daha yüksek oranda tükenmişlik yaşadığını göstermektedir. ${ }^{16,17}$ Aktuğ ve arkadaşlar1 ${ }^{18}$ ile Oray ve arkadaşları $^{19}$ çalışmalarında, araştırma görevlilerinin daha çok DT ve D alt boyutlarında tükenmişlik yaşadıklarını saptamışlardır. Uzmanlık eğitimi döneminde, çalışma saatlerinin uzun olması, sık nöbet tutulması, uykusuzluk, öğrenilmesi gereken bilginin fazla oluşu, deneyim eksikliği gibi pek çok faktör tükenmişliğe neden olabilir.

Çalışmamızda, cerrahi tıp bilimlerdeki hekimlerin, pozitif, negatif, toplam defansif tıp, 
İBG, D puan ortalamaları, dahili tıp bilimlerindeki hekimlere göre anlamlı derecede yüksek çıkmıştır. Her iki grup arasında DT ve KB için anlamlı fark saptanmamıştır. Aynacı'nın yapmış olduğu çalışmada da pozitif ve negatif DTU yöntemlerinin hemen hepsinde, cerrahi tıp bilimlerdeki hekimlerin DTU oranları, dahili tıp bilimlerdekilerden yüksek çıkmıștır. ${ }^{2}$ Asher ve arkadaşları ${ }^{13}$ yaptı̆̆ cerrahi bilimlerdeki hekimler anlamlı derecede daha fazla defansif tıp uygularken, O'leary ve $\operatorname{arkadaşları~}^{20}$ yaptığı çalışmada, PDT oranları açısından, dahili ve cerrahi tıp bilimler arasında fark görülmemiş, NDT düzeyi cerrahi tıp bilimlerinde anlamlı olarak daha yüksek çıkmıştır.

Erol ve arkadaşları yaptığ çalışmada, bulduğumuz sonuçla uyumlu olacak şekilde, cerrahi bilimlerde çalışan araştırma görevlilerinin D açısından, dahili bilimlerde çalışanlara göre daha tükenmiş oldukları saptanmıştır. ${ }^{21}$ Cerrahi bilimlerde çalışan araştırma görevlilerinin, zamanlarının çoğunu ameliyathanede geçirmeleri ve genellikle hastalarıyla yüz yüze konuşmaya nispeten yeterince vakit ayıramamaları nedeniyle D’ye daha yatkın oldukları düşünülebilir.

Araştırmamızda, erkeklerin, pozitif, negatif ve toplam defansif puan ortalamaları, kadınların aldıkları puan ortalamalarına göre anlamlı derecede yüksek çıkmıştır. Aynacı'nın yaptığı çalışmada da, birçok defansif uygulama yönteminde erkekler, kadınlara göre daha fazla defans uyguladıklarını belirtmiştir. ${ }^{2}$ Moosazadeh ve arkadaşlarının $^{7}$ yaptığı çalışmada, kadınların, erkeklere göre daha fazla NDT uyguladığ 1 , diğer bazı çalışmalarda ise cinsiyet ile DTU oranı arasında anlamlı bir ilişki olmadığını görülmektedir. ${ }^{22,23}$ Çalışmamızda, cerrahi branşların DTU'nı daha fazla yapıyor olması ve cerrahi bilimlerdeki katılımcıların çoğunun erkek olması, bu bulgumuzun arkasindaki nedendir. Cinsiyete göre, İBG düzeyi arasında fark olmadığ1 sonucumuz, Aslan ve arkadaşları çalışmasıyla uyumlu bulunmuştur. ${ }^{4}$

Bu çalışmada, yaş ile DTU düzeyi arasında anlamlı ilişki bulunmamasına karşın, birçok çalışmada 40 yaş altındaki hekimlerin defansif tıp uygulama düzeyleri, 40 yaş üzerindekilere göre anlamlı derecede yükssek çıkmıştır. ${ }^{15,22}$ Catino'ya göre genç hekimler mesleki tecrübe eksikliğinden dolayı daha fazla defansif tıp uygulamaktadır. ${ }^{24}$ Çalışmamızdakine benzer şekilde; Sünter ve arkadaşları ${ }^{25}$ ile Arıkan ve arkadaşları, ${ }^{26}$ yaptıkları çalışmalarda, ileri yaştakilerde İBG'in daha fazla olduğu sonucuna ulaşılmıştır. Maslach'a göre, yaş, tükenmişlik ile ilgili en tutarlı değişkendir. Yaşın, tükenmişlikten koruyucu bir faktör olduğu düşünülse de tükenmişliği artırdığını gösteren çalışmalar da mevcuttur. ${ }^{10}$ Çalışmamızla uyumlu olarak, Sünter ve arkadaşları çalışmasında, yaşın, tükenmişlik üzerine etkisi olmadığı tespit edilmiştir. Çalışmamızda, uzmanlık eğitiminin ilk 2 yılında olan hekimlerin PDT, NDT, TDT ve DT puanlarının ortalamaları, uzmanlık eğitiminin 3-5. yılında olan hekimlere göre anlamlı derecede yüksekti. Uzmanlık eğitiminin ilk yıllarında, iş yükünün daha fazla olması, yeterli tecrübelerinin bulunmamas1, üstlerinden yeterince takdir görememesi ve ayrıca yeni başlayan bireylerin iş konusunda daha heyecanlı ve istekli olmaları nedeniyle daha fazla enerji harcayarak daha kısa zamanda yorulmaları gibi nedenlerden dolayı DT'nin daha yüksek düzeyde yaşanmasını açıklayabilir.

Çalışmamız, hem yurt içi hem de yurtdışı çalışmalardaki, hakkında daha önce malpraktis davası açılması ile DTU düzeyinin, açılmayanlara göre daha yüksek olduğu bilgisini desteklemektedir. ${ }^{2,13}$

Sigara kullanımı ile defansif tıp, İBG, DT, D puanları arasında, alkol kullanımı ile İBG, DT, D arasında anlamlı ilişki bulunmuştur. Hakkında, malpraktis davası açılanların DTU oranlarının, açılmayanlara göre yüksek bulunması ve defansif tıp ile İBG ve tükenmişlik arasındaki korelasyonlar da dikkate alındığında, bu maddelerin kullanımının, açılan veya açılması olası bir malpraktis davasının yarattığ 1 endişe, İBG ve tükenmişliğin bir sonucu olarak gündeme gelmesi akla yatkın gelmektedir.

Sigara ve/veya alkol kullanma ile İBG düzeyinin yüksekliğinin birlikteliğini gösteren çalışmalar mevcuttur. ${ }^{26}$ Hellerstedt ve Jeffery'e göre İBG, daha fazla sigara içmeye neden olmaktadır. ${ }^{27}$ Çalışmamızla uyumsuz olarak, ülkemizde yapılan çalışmaların çoğunda sigara/alkol kullanımı ile, tükenmişlik arasında bir ilişki bulunamamıştır. Goldberg ve arkadaşları ${ }^{28}$ ise, acil servis çalışanları üzerinde yaptıkları araştırmada yüksek alkol tüketiminin tükenmişliği arttırdığını belirtirken, Toral-Villanueva ve arkadaşları $^{29}$ yaptığı çalışmada sigara ve alkol kullanımı ile tükenmişlik arasında anlamlı bir ilişki bulunamamıştır. Literatürde, sigara ve alkol kullanımı ile tükenmişlik arasındaki neden sonuç ilişkisi net olarak ortaya konulamamıştır.

Defansif tıbbın, dünya genelindeki yaygınlığı ve birçok çalışmada, pozitif ve negatif defansif uygulamaların ikisinin de benzer oranlarda görülmesi, çalışmamızdaki gibi PDT'yi sık uygulayan hekimlerin, aynı zamanda NDT'yı da benzer oranda uyguladığını göstermektedir. Çalışmada, defansif tıp ile tükenmişlik arasında zayıf bir korelasyon görülse de bu konudaki ilişkinin ortaya konabilmesi için daha çok çalışmaya ihtiyaç vardır. İBG'nin artması ile DT ve 
D'nin artması, KB'nin azalması literatürle uyumludur.

Hekimlikte, branş seçerken yeteri kadar önem vermek ve zaman ayırmak gerekir. Tercih edilmesi düşünülen dalda çalışan diğer hekimlerle görüşmek, imkanlar dahilinde o dalda bir süre çalışmak, o dal hakkında çalışma koşullarını daha iyi anlamaya, kişinin kendi beklentilerine uyup uymaması açısından daha doğru değerlendirmesine yardımcı olabilir ${ }^{30}$.

Tibbın gelişiminin takibi ve yeni bilgilerin hasta yararına uygulanması adına, mezuniyet sonrası hekimin kendi alanıyla ilgili bilgi, becerisini güncel tutabilmesi sağlanmalıdır. Tıbbi malpraktis için, özel hukuki düzenlemelerin yapılması gerekir. Hekimler, trafik kazası, cinayet gibi suçlarla yargılanan kişilerin, yargılandığ yargılanmamalıdır. $\mathrm{Bu}$ nedenle sağlık sistemini düzenleyen tüm yönetmelik, kararname, genelge ve kanunlara dengeli ve hassas hazırlanmış tıbbi malpraktis kanunları da eklenerek tek çatı altında güncel hale getirilmesi uygun olacaktır. Sonuçlanmayan davaların, medyada geniş yer bulması engellenmeli, sağlıkta şiddeti önleyici, caydırıcı yasalar çıkarılmalıdır. ${ }^{31}$

Çalışmamızın bölgesel nitelikte olması, ülke geneli, diğer kamu ve özel hastaneler veya hekimlik mesleğindeki pratisyen, uzman, yandal uzmanı, akademisyen gibi farklı pozisyonlarda çalışan hekimler için genellenemeyişi, örneklem grubumuzun nispeten genç hekimlerden oluşması ve meslekte çalışma sürelerinin daha kısa olması, verilerin araştırma görevlilerinden toplanması çalışmamızın kısıtlıklarıdır.

\section{SONUC}

Hekimlerde, erkek cinsiyet, uzmanlık eğitiminin ilk 2 y1lı içerisinde ve cerrahi branşta olma, nöbet sayısının fazla olması, hakkında malpraktis iddiasıyla dava açılmış olması, sigara bağımlılığı, tükenmişlik ve işe bağlı gerginlik düzeylerinin defansif tıp uygulama oranlarının yüksek olmasında etkili olduğu düşünülmüştür. Hekimlerin, çalışma ortamlarının ve fiziksel koşullarının daha sağlıklı hale getirilmesi, nöbet sayılarının makul düzeylere çekilmesi, nöbet sonrası izin hakları sağlanması, iş yaşamlarında stres yönetimi, sorunlarla baş etme gibi konularda eğitim programlarının düzenlenmesi, düzenli bir şekilde uygulanması ayrıca hukuki uygulamalar konusunda eğitimler verilmesi gerekmektedir.

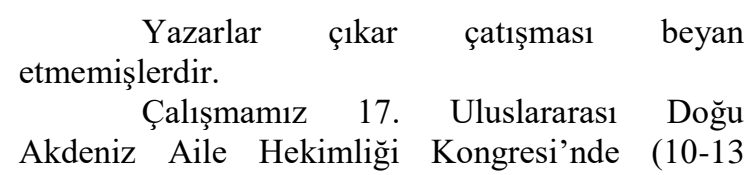

Mayıs 2018, Sheraton Grand Otel - Adana) sözel bildiri olarak sunulmuştur.

\section{KAYNAKLAR}

1. Hermer LD, Brody H. Defensivemedicine, costcontainmentand reform. Journal of General InternalMedicine 2010;25(5):470-3.

2. Aynacı Y. Hekimlerde Defansif (Çekinik) Tıp Uygulamalarının Araştırılması. Selçuk Üniversitesi Meram Tıp Fakültesi, Adli Tıp Uzmanlık Tezi. Konya: 2008:3.

3. Sethi MK, Aseltine RH.Investigation of defensive medicine in Massachusetts, presented at the Massachusetts Medical Society 2008.2-8.

4. Aslan SH, Aslan RO, Kesepara C, Alparslan ZN, Ünal M. Kocaeli'de bir grup sağlık çalışanında işe bağlı gerginlik, tükenme ve iş doyumu. Toplum ve Hekim Dergisi. 1997;82(12):24-29.

5. Savul G. Güvencesiz istihdam, örgütsel dönüşüm ve çalışma üzerine etkisi. Ankara Üniversitesi Sosyal Bilimler Enstitüsü, Yüksek Lisans Tezi. Ankara:2008.108.

6. Başer A, Başer Kolcu MI, Kolcu G, Gök Balcı U. Defansif Tıp Uygulamaları Tutum Ölçeğinin Türkçe Formunun Geçerlilik ve Güvenilirliği: Ön Çalışma. Tepecik Eğit Hast. Derg. 2014;24(2):99-102.

7. Moosazadeh M, Movahednia M, Movahednia N, Amiresmaili M, Aghaei I.Determiningthefrequency of defensivemedicine among general practitioners in Southeast Iran. Int $\mathbf{J}$ HealthPolicyManag. 2014;2(3):119-23.

doi: 10.15171/ijhpm.2014.28.

8. Revicki DA, May HJ, Whitley TW. Reliabilityandvalidity of theWorkRelatedStrain Inventory amonghealthprofessionals. BehavMed. 1991;17(3):111-20.

9. Aslan SH, Alparslan ZN, Aslan RO, Kesepara C, Ünal M. İşe Bağlı Gerginlik Ölçeğinin Sağlık Alanında Çalışanlarda Geçerlik ve Güvenirliği. Düşünen Adam. 1998;11(2):4-8.

10. Ergin C. Doktor ve Hemşirelerde Tükenmişlik ve Maslach Tükenmişlik Ölçeğinin Uyarlanması. VII. Ulusal Psikoloji Kongresi Bilimsel Çalışmaları. Ankara:Türk Psikologlar Derneği Yayını; 1992. p.143-154.

11. Marakoğlu K, Kargın NÇ, Armutlukuyu M. Tip fakültesiaraştırmagörevlilerindetükenmişliksen dromuveilişkilifaktörlerindeğerlendirilmesi. Genel Tip Derg. 2013;23:102-8.

12. Chen $\mathrm{KY}$,Yang $\mathrm{CM}$, Lien $\mathrm{CH}$, Chiou HY,Lin MR,Chang HR et al.Burnout, JobSatisfaction, 
andMedicalMalpracticeamongPhysicians. Int $\mathbf{J}$ MedSci. 2013;10(11):1471-78.

13. Asher E, Greenberg-Dotan S, Halevy J, Glick S, Reuveni H.DefensiveMedicine in Israel- A NationwideSurvey. PlosOne. 2012;7(8): e42613.

14. Studdert DM, Mello MM, Sage WM, Desroches CM, Peugh J, Zapert K, et al.Defensivemedicineamonghigh-risk specialistphysicians in a volatilemalpracticeenvironment. JAMA. 2005;293(21):2609-17.

15. Ortashi O, Virdee J, Hassan R, Mutrynowski T, Abu-Zidan F.Thepractice of defensivemedicineamonghospitaldoctors in the United Kingdom. BMC MedicalEthics. 2013 Oct 29;14:42. doi: 10.1186/1472-6939-14-42.

16. Dyrbye LN, Varkey P, Boone SL, Satele DV, Sloan JA, Shanafelt TD. Physiciansatisfactionandburnout at differentcareerstages. Mayo ClinProc. 2013;88(12):1358-67. doi: 10.1016/j.mayocp.2013.07.016.

17. Wang Z, Xie Z, Dai J, Zhang L, Huang Y, Chen B. Physician burnout and it's associated factors: a cross-sectional study in Shangai. J OccuptHealth. 2014;56(1):73-83.

18. Aktuğ IYY, Susur A, Keskin S, Balcı Y, Seber G, Günay Y. Osmangazi Üniversitesi Tip Fakültesinde çalışan hekimlerde tükenmişlik düzeyleri. Osmangazi Tıp Dergisi. 2006;28(2):91-101.

19. Çolak ON, Balcı B, Özlem EN, Özaçar E, Abalı L, İbış MA ve ark. Dokuz Eylül Üniversitesi Tıp Fakültesi Tıpta Uzmanlık Öğrencilerinin Mesleki Tükenmişlik Düzeyleri. Dokuz Eylül Üniversitesi Tip Fakültesi Dergisi. 2013;27(2):67-73.

20. O’leary KJ, Choi J, Watson K, Williams MV. Medical students' and residents' clinical and educational experiences with defensive medicine. Acad Med. 2012;87(2):142-8. doi:10.1097/ACM.0b013e31823f2c86.

21. Erol A, Sarıçiçek A, Gülseren Ş. Asistan hekimlerde tükenmişlik: İş doyumu ve depresyonla ilişkisi. Anadolu psikiyatri dergisi. 2007;8(4):241-47.

22. Solaroglu I, Izci Y, Yeter HG, Metin MM, Keles GE. Health transformation Project and defensive medicine practice among neurosurgeons in Turkey. Plos One. 2014; 9(10):e111446.

doi: 10.1371/journal.pone.0111446.

23. Tanriverdi O, Cay- Senler F, Yavuzsen T, Turhal S, Akman T, Komurcu S, et al. Perspectives and practical applications of medical oncologists on defensive medicine (SYSIPHUS study): a study of the Palliative Care Working Committee of the Turkish Oncology Group (TOG). Med Oncol. 2015;32(4):106. doi: 10.1007/s12032-0150555-5.

24. Catino M. Why do physicians practice defensivemedicine.The side- effects of madicall itigation. Safety science monitor. 2011;15(1):1-12.

25. Sünter AT, Canbaz S, Dabak Ş, Öz H, Pekşen Y. Pratisyen hekimlerde tükenmişlik, işe bağlı gerginlik ve iş doyumu düzeyleri. Genel Tıp Derg. 2006;16(1):9-14.

26. Arıkan D, Karabulut N. Hemşirelerde ișe bağlı gerginlik ve bunu etkileyen faktörlerin belirlenmesi. Atatürk üniversitesi hemşirelik yüksekokulu dergisi. 2004;7(1):10-16.

27. Hellerstedt WL, Jeffery RW. The association of jobs train and health behaviours in men and women. Int J Epidemiol. 1997;26(3):575-83.

28. Goldberg R, Boss RW, Chan L, Goldberg J, Mallon WK, Moradzadeh D, et al. Burnout and its correlates in emergency physicians: four years' experience with a wellness booth. Acad Emerg Med. 1996;3(12):1156-64

29. Toral-Villanueva R, Aguilar-Madrid G, JuárezPérez CA. Burnoutandpatientcare in juniordoctors in Mexico City. OccupMed(Lond). 2009;59(1):8-13. doi: 10.1093/occmed/kqn122.

30. Yoney H, Yavuz DG, editörler. Tipta Uzmanlık Seçimi.1. Baskı. İstanbul: Marmara Üniversitesi Yayınlar1; 2010.p.12.

31. Altun G, Yorulmaz AÇ. Yasal değişiklikler sonrası Hekim sorumluluğu ve Malpraktis. Trakya Üniversitesi Tıp Fak. Dergisi. 2010;1(27):7-12. 